\title{
Quantitative Characterization of Activated Carbon from Cow, Donkey, Chicken and Horse Bones from Ezzangbo in Ebonyi State, Nigeria
}

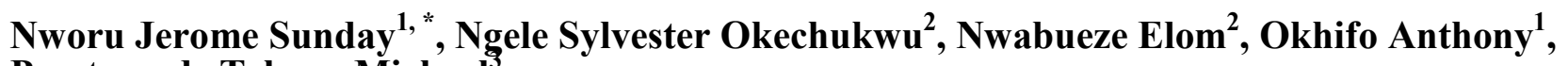 \\ Peretomode Tekena Michael $^{3}$ \\ ${ }^{1}$ Department of Chemistry, Nigeria Maritime University, Delta, Nigeria \\ ${ }^{2}$ Department of Industrial Chemistry, Ebonyi State University, Abakaliki, Nigeria \\ ${ }^{3}$ Department of Chemical Engineering, Delta State University, Abraka, Nigeria \\ Email address: \\ Jeromenworu102@gmail.com (N. J. Sunday) \\ ${ }^{*}$ Corresponding author
}

\section{To cite this article:}

Nworu Jerome Sunday, Ngele Sylvester Okechukwu, Nwabueze Elom, Okhifo Anthony, Peretomode Tekena Michael. Quantitative Characterization of Activated Carbon from Cow, Donkey, Chicken and Horse Bones from Ezzangbo in Ebonyi State, Nigeria. American Journal of Applied Chemistry. Vol. 6, No. 5, 2018, pp. 169-174. doi: 10.11648/j.ajac.20180605.12

Received: October 10, 2018; Accepted: October 24, 2018; Published: November 19, 2018

\begin{abstract}
Animal bones have been used to produce carbon char for quality assessment of activated carbon over non activated carbon (used as sample control) as influenced by method of activations (acid and heat). In this study samples analyzed were carbonized in a closed crucible at $400^{\circ} \mathrm{C}$ and ground into powder after cooling. $200 \mathrm{~g}$ of each of the crushed samples was activated using $250 \mathrm{ml}$ of $2 \mathrm{M}$ Hydrochloric acid for one hour at $80^{\circ} \mathrm{C}$ and another $200 \mathrm{~g}$ was activated by thermal method at $120^{\circ} \mathrm{C}$ for 3 hours. To obtain the optimum weight lost of the carbons, the carbonization period was varied from 0.5 3hours. From the result, increase in carbonization time caused an appreciable increase in the percentage weight loss, this reached a maximum value at a carbonization time of 2.5 hours for both carbon samples at a corresponding percentage weight lost of $63 \%, 58 \%, 54 \%$ and $62 \%$ for cow, donkey, chicken and horse bones respectively. The percentage of carbon yield of cow, donkey, chicken and horse bones upon acid activation are in increasing order of cow $(48.92 \%)>$ horse $(48.64 \%)>$ donkey $(46.34 \%)>\operatorname{chicken}(44.80 \%)$ bones and horse $(37.03 \%)>\operatorname{cow}(36.21)>\operatorname{donkey~}(34.96 \%)>$ chicken $(30.18 \%)$ upon heat activation. Among the bone samples, chicken bone has the least ash content of $12.84 \%, 11.05 \%$ and $15.84 \%$ for acid, heat and non-activated samples respectively. The difference in bulk densities of acid activated and heat activated carbons are infinitesimal. The order of increasing bulk densities is cow $\left(0.80 \mathrm{~g} / \mathrm{m}^{3}\right)>$ donkey $\left(0.78 \mathrm{~g} / \mathrm{m}^{3}\right)=$ horse $\left(0.78 \mathrm{~g} / \mathrm{m}^{3}\right)>$ chicken $\left(0.49 \mathrm{~g} / \mathrm{m}^{3}\right)$. The heat activated carbons shows higher percentage of hardness than the acid activated and non-activated carbons. This study indicated that activated carbons from Cow, Donkey, Chicken and Horse are effective as adsorbents with those obtained from chicken having better features of adsorbents.
\end{abstract}

Keywords: Charcoal, Activated Carbon, Carbonization, Adsorbent

\section{Introduction}

Charcoal is a carbonized substance used mainly as fuel in industry. Charcoal is used to reduce oxidized iron and in steel production. The production of gun powder containing $15 \%$ charcoal was seen as the drive for further research in charcoal [1]. This led to different researches on different carbon containing organic matter such as animal bones and higher plants and their production processes is aimed at low ash content to enhance clean combustion. Charcoal as a smokeless fuel is used mainly in heating and steel production [2].

Carbonization means obtaining charcoal from the raw material and the produced charcoal having low surface area to volume ratio is not an active product. It involves the conversion of organic containing residue into carbon or a carbon containing residue through pyrolysis. Carbonization of raw material is carried out in an oxygen free environment 
at a temperature of about $500^{\circ} \mathrm{C}-700^{\circ} \mathrm{C}$ [3]. Carbonization is an exothermic process and can be made self-sustaining and used as a source of energy which does not produce carbon dioxide [2]. Activated carbon is a porous, black carbonaceous material. It is distinguished from elemental carbon by the absence of both impurities and an oxidized surface. There are two basic processes for the preparation of activated carbon; physical or thermal activation and chemical activation. Physical activation involves the use of air, carbon dioxide or water vapor at high temperature while the chemical activation process makes use of activating agents such as phosphoric acid $\left(\mathrm{H}_{3} \mathrm{PO}_{4}\right)$ or zinc chloride $\left(\mathrm{ZnCl}_{2}\right)$ [8]. Though, there are many commercially available activated carbon, these are still quite expensive [9, 10]. Various researchers [10-15] have carried out studies for simplified and cost effective methods of activation. Activated carbon has an extra-ordinarily large surface area and pore volume, which makes it suitable for a wide range of application.

Activated carbon are mainly used in adsorption processes. The total number of pores, their shapes and sizes determine the adsorption capacity and the dynamic adsorption rate of the activated carbon [4].

Other applications include removal of odor, water purification, color removal and as a purifying agent in food processing. According to Guo and Lua (2001), the characteristics of activated carbon depend on the physical and chemical properties of the raw materials and the activation method used. The physical properties of a given activated carbon are important in determining their specific applications. For instance, the ash content reflects the purity of the carbon. Also, the ash content can be important in water filtration applications. Activated carbon with high phosphate ash can bring about cloudy water during use because the ash could combine with metal ions in the water to form calcium and magnesium precipitates [6]. The pore volume is important in gas adsorption. It is the micro pore volumes in activated carbon which have the greatest influence upon adsorption of gases while macro pores and meso pores are important in transport of fluids [7]. The important factor that affects the adsorption capacity of activated carbon is its moisture content. By normal convention, a high moisture content of more than $3-5 \%$ is considered not good for normal applications [16].

\section{Materials and Methods}

\subsection{Sample Collection and Charcoal Preparation}

The bone samples of cow, donkey, chicken and horse were collected from a local slaughter house in Ezzangbo, Abakaliki, Nigeria. Samples were washed and oven dried at $105^{\circ} \mathrm{C}$. Accurately weighed and dried bone samples of cow, donkey, chicken and horse were carbonized in a closed crucible at $400^{\circ} \mathrm{C}$, using Fisher Scientific Isotemp Muffle Furnace, for 1 hour.

To investigate the effect of carbonization time of carbon weight lost, the samples were allowed in the furnace at varying periods ranging from 30 minutes to 3 hours at a temperature of $400^{\circ} \mathrm{C}$. The carbonized samples were ground and sieved to $2 \mathrm{~mm}$ size.

Preparation of Activated Carbon

The carbonized bone was then activated by measuring $200 \mathrm{~g}$ of each of the crushed samples into a beaker which was then made into sludge with $250 \mathrm{ml}$ of $2 \mathrm{M}$ hydrochloric acid. The resulting mixture was heated for one hour at $80^{\circ} \mathrm{C}$, filtered off and washed with distilled water to remove the acid on the surface of the carbons and then dried in an oven at $105^{\circ} \mathrm{C}$ for 24 hours. The dried sample was sieved to $2 \mathrm{~mm}$ size and kept in a small tray. This procedure was done for all carbonized bone sample.

\subsection{Characterization of the Activated Carbon}

\subsubsection{Moisture Content}

The weight of the empty crucible was recorded as $\mathrm{W}_{1} .2 \mathrm{~g}$ of sample was weighed into a crucible and the weight of sample plus crucible was noted as $\mathrm{W}_{2}$. The sample was dried in an oven at $105^{\circ} \mathrm{C}$ for 24 hours. It was removed, placed in a desiccator and allowed to cool. The sample plus crucible was weighed again and it was noted as $\mathrm{W}_{3}$. It was repeated twice for all samples to obtain average moisture content value. The estimated value of the moisture content was calculated thus;

$$
\frac{\mathrm{W}_{2}-\mathrm{W}_{3}}{\mathrm{~W}_{2}-\mathrm{W}_{1}} \times 100
$$

\subsubsection{Ash Content}

A $2 \mathrm{~g}$ of dry activated sample was weighed and recorded as $\mathrm{W}_{0}$, the $2 \mathrm{~g}$ of dry samples were placed in a crucible, weight of crucible plus dry sample was noted and recorded as $\mathrm{W}_{2}$. The sample was then placed in a furnace at $500^{\circ} \mathrm{C}$ for 6 hours. After which it was removed, placed in a crucible and its content reweighed and recorded as $\mathrm{W}_{3}$. The process was repeated twice for all the activated carbon samples, and the estimated value of the ash content was calculated thus;

$$
\frac{\mathrm{W}_{2}-\mathrm{W}_{3}}{\mathrm{~W}_{0}} \times 100
$$

\subsubsection{Bulk Density}

The sample was transferred into a cylinder of $10 \mathrm{ml}$ and the weight of the sample plus cylinder was recorded as $\mathrm{W}_{2}$. The estimated value of the bulk density was calculated thus;

\section{Weight of Sample (W2) \\ Weight of equal Volume of Water}

\subsubsection{Pore Volume}

A $2 \mathrm{~g}$ of activated carbon was weighed into a beaker and the weight of sample plus beaker was noted as $\mathrm{W}_{1} .50 \mathrm{ml}$ of distilled water was transferred into the beaker containing the dry sample and the mixture was boiled for 15 minutes. After the air in the pores has been displaced, the sample was drained, dried superficially and weighed. The weight was recorded as $\mathrm{W}_{\mathrm{F}}$ and the procedure was repeated twice. The estimated value of the pore volume was calculated thus; 


$$
\frac{\mathrm{W}_{\mathrm{F}}-\mathrm{W}_{1}}{\mathrm{~W}_{1}} \times \text { Density of water }
$$

\subsubsection{Fixed Carbon}

The fixed carbon content of each sample was estimated thus (assuming sulphur content was negligible):

$$
\frac{\mathrm{Y}_{\mathrm{ch}}-\mathrm{AC}-\mathrm{MC}}{\mathrm{Y}_{\mathrm{ch}}} \times 100
$$

Where; Ych is the yield of charcoal, AC is the ash content and $\mathrm{MC}$ is the moisture content

\subsubsection{Hardness}

The carbon hardness was determined according to ASTM (2002) method. This involves measuring $2 \mathrm{~g}$ of carbon sample in a standard sieve number 40 . The sieve was shaken for 1 hour using mechanical shaker (Milano Italia-type) at 160 revolutions per minutes (rpm) with four steel balls of $6.00 \mathrm{~mm}$ diameter each inside the sieve. The amount of activated carbon retained in the sieve after 1hour was expressed in percentage.

\subsubsection{Yield of Charcoal}

The yield of charcoal was estimated thus,

$$
\frac{\mathrm{W}_{0}-\mathrm{AC}+\mathrm{MC}}{\mathrm{W}_{0}} \times 100
$$

Where, $\mathrm{W}_{0}$ is the original weight of dry sample, $\mathrm{AC}$ is the ash content, $\mathrm{MC}$ is the moisture content.

\section{Results}

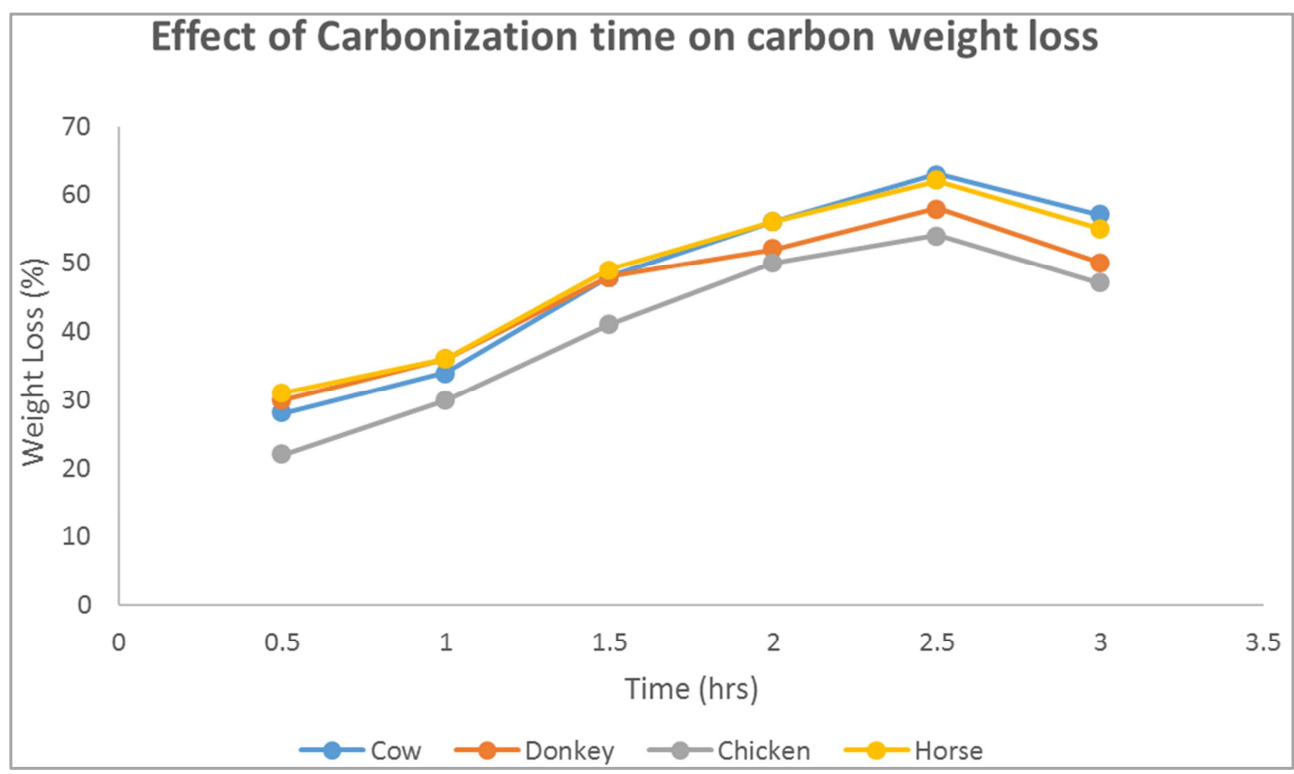

Figure 1. Effect of Carbonization time on carbon weight lost

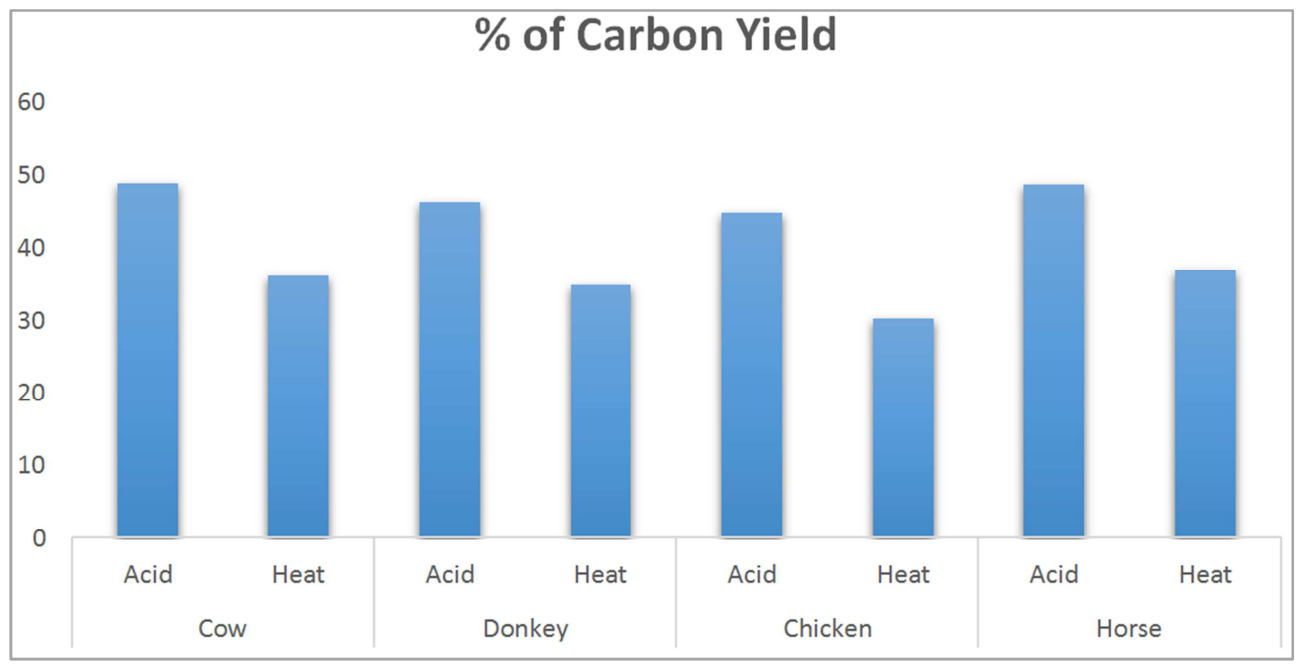

Figure 2. Percentage of Carbon yield with different Activating Agents. 


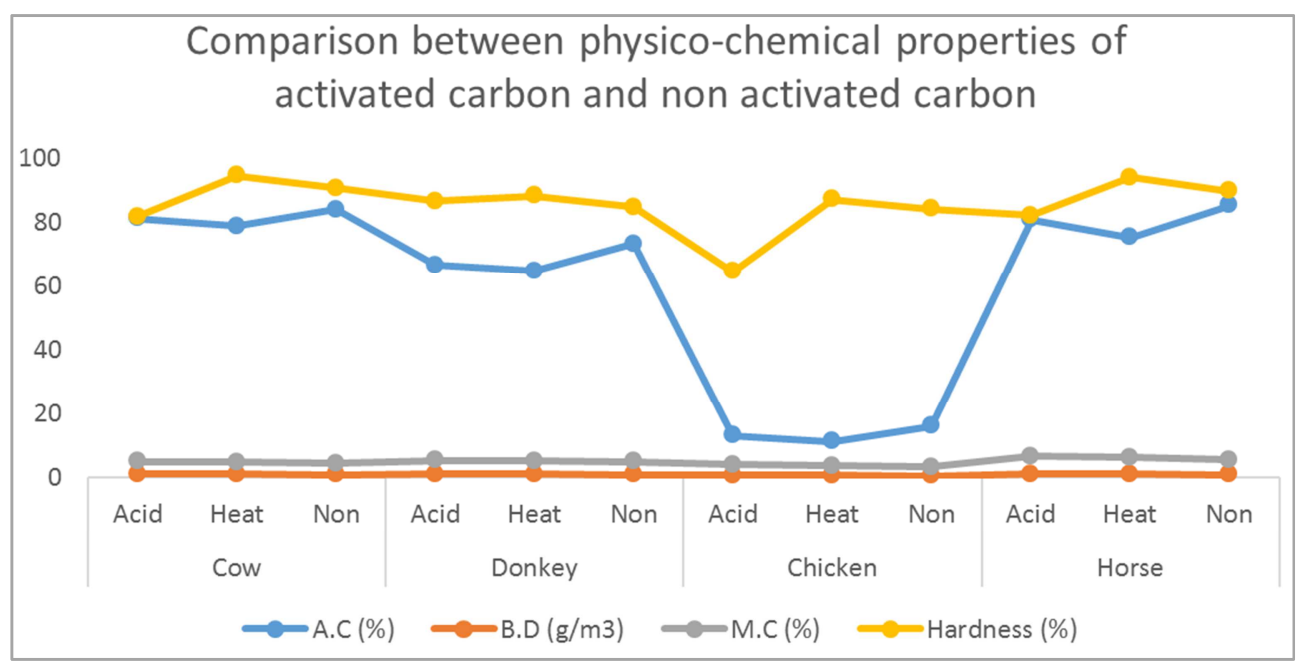

Figure 3. Comparison between physico-chemical properties of activated carbon and non-activated carbon.

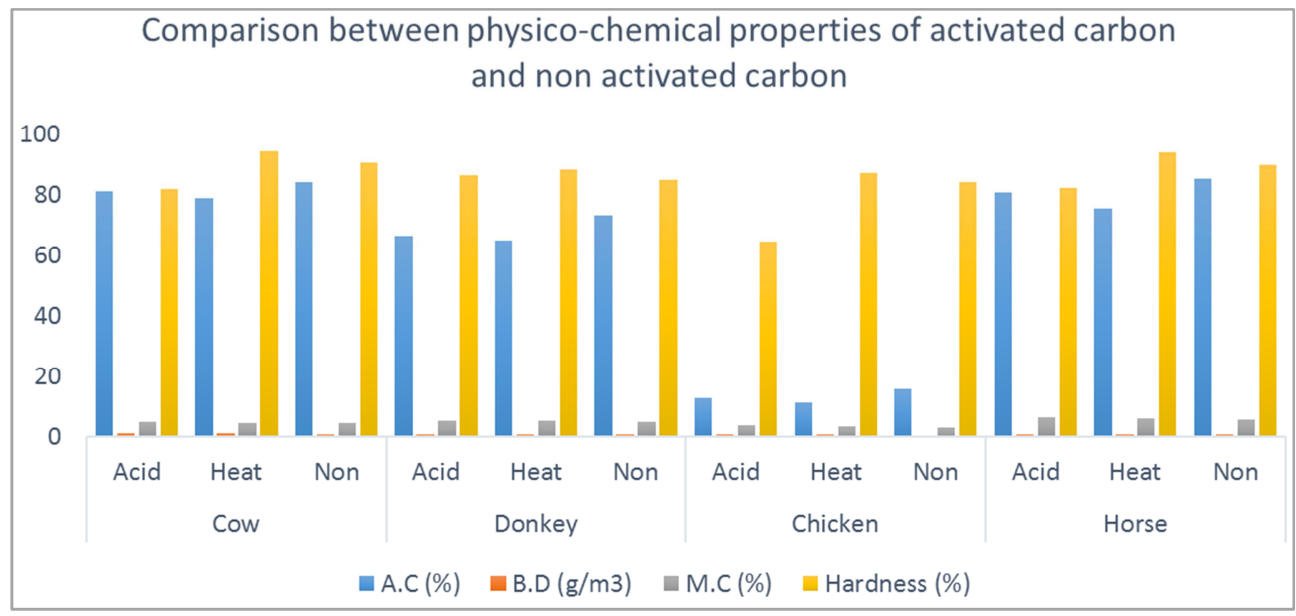

Figure 4. Comparison between physico-chemical properties of activated carbon and non activated carbon.

\section{Discussions}

The percentage yields of bone samples of cow, donkey, chicken and horse based charcoal were $45.15 \%, 44.17 \%$, $40.88 \%$ and $45.66 \%$ respectively after carbonization. Figure 1 shows the percentage weight lost as a result of varying carbonization time of various carbon samples at $400^{\circ} \mathrm{C}$ in a furnace. From the results, increase in carbonization time caused an appreciable increase in the percentage weight lost, this reached a maximum value at a carbonization time of 2.5 hours for both carbon samples at a corresponding percentage weight loss of $63 \%, 58 \%, 54 \%$ and $62 \%$ for cow, donkey, chicken and horse bones respectively. This time of maximum percentage weight loss is in agreement with another research [17]. Increase in weight loss on each of the carbon sample is as a result of loss of volatile matter of heat labile substances [18]. Also, the rapid decrease in percentage weight loss after 2.5 hours (maximum time of weight loss) shows the beginning of activation of the already formed carbon. Similar observations were reported in other researches [18, 22]. According to them, pore structure is developed followed by porosity formation and decrease in weight losses during carbonization processes.

Figure 2 shows Percentage of Carbon yield with different Activating Agents. Product yield is an important measure of the feasibility for preparing activated carbon from a given carbonaceous substance [19]. High product yield difference is as a result of the origin of carbon material and activation processes [5]. The percentage of carbon yield of cow, donkey, chicken and horse bones upon acid activation are in increasing order of cow $(48.92 \%)>$ horse $(48.64 \%)>$ donkey $(46.34 \%)>$ chicken $(44.80 \%)$ bones and horse $(37.03 \%)>$ cow $(36.21)>$ donkey $(34.96 \%)>$ chicken $(30.18 \%)$ bones upon heat activation. The results of acid and heat activations processes show that acid activation gives higher yield of carbon. These results are in agreement with the findings of other researches [17, 19, 21, 24] who reported that percentage carbon yield for most carbon containing substances when activated is in the range of 39.99 to $55.44 \%$. This research showed that bones of cow, donkey, chicken and horse have high percentage carbon yield.

Figures 3 Comparison between physico-chemical properties of activated carbon and non-activated carbon. Activation reduces the ash content of carbons. This is attributed to the volatilization of some inorganic materials 
during activation at higher temperature [22]. Also, acids used in the activation process can react with the mineral contents of the carbon thereby reducing the ash content during activation $[9,11,17,22]$. From the result, the ash content of the bone samples was higher in non-activated bone char while heat activated carbons have the least ash contents. Among the bone samples, chicken bone has the least ash content of $12.84 \%, 11.05 \%$ and $15.84 \%$ for acid, heat and non-activated samples respectively. For adsorbent to be effective in application, it must possess low ash content [22]. The ash contents of cow and horse bones were averagely the same and have the highest ash contents. Acid treatment has been reported to reduce high ash levels of bituminous and lignite carbon [23]. The result also shows that; the acid activated carbon has higher ash content than heat activated carbons. This could be due to the residuals of the acid which may remain with the carbon as ash. This finding is in agreement with the report on sub-bituminous and lignite carbons treated with acid [21, 23].

High carbon yield, high fixed carbon, high bulk density, increased surface area, Low ash content, low moisture content and low pore volume of carbon gives effective adsorbent for industrial applications [15, 18, 22]. Activated carbons showed higher bulk densities. The difference in bulk densities of acid activated and heat activated carbons are infinitesimal and negligible. The order of increasing bulk densities is cow $\left(0.80 \mathrm{~g} / \mathrm{m}^{3}\right)>$ donkey $\left(0.78 \mathrm{~g} / \mathrm{m}^{3}\right)=$ horse $\left(0.78 \mathrm{~g} / \mathrm{m}^{3}\right)>$ chicken $\left(0.49 \mathrm{~g} / \mathrm{m}^{3}\right)$. The densities observed in these carbon samples are in consonance with the values of 0.35 to $1.2 \mathrm{~g} / \mathrm{m}^{3}$ reported for other carbonaceous materials [18]. The activated carbons have higher moisture contents. This observation is in agreement with other studies [17]. The heat activated carbons show higher percentage of hardness than the acid activated and non-activated carbons (Figure 3). This indicates that higher temperature treatment of carbons have significant effect on their abrasion resistance and could be applied where frequent washing is needed. The result of the hardness is in agreement with other studies $[6,17]$.

\section{Conclusion}

This study indicated that activated carbons from Cow, Donkey, Chicken and Horse are effective as adsorbents with regard to their evaluated properties of moisture content, ash content, bulk density, fixed carbon, hardness and percentage yield. Activated carbon gotten from chicken having low ash content is a good indication of a better adsorbent. The adsorptive efficiency of each of the carbon can be enhanced through controlled and well monitored activation.

\section{References}

[1] Gray, E., Marsh, H. and McLaren, M. (1982): A Short History of Gunpowder and the role Charcoal in its Manufacture. J. Mater. Sci., 17: 3385-3400.

[2] Brown, R., del Campo, B., Boateng, A. A., Garcia-Perez, M. and Masek, O. (2015): Fundamentals of Biochar Production. In Biochar for Environmental Management: Science, Technology and Implementation; Lehmann, J. Joseph, S., Eds., Routledge: Oxford, UK. $1^{\text {st }}$ Edition. Pp 23-25.

[3] Dilect, C. and Oznuh, A. Y. (2008): Production and Characterization of Activated Carbon from Bituminous Coal through Chemical Activation. Afr. J. Biotechnol., 7(2): 37033710 .

[4] Ashford, R. D, (1994). Ashford's Dictionary of Industrial Chemicals, London: Wavelength Publisher Ltd. $2^{\text {nd }}$ Edition. 1(2): 1011-1019.

[5] Guo, J. and Lua, A. C. (2001): Characterisation of Adsorbents prepared from Oil Palm Shell by Thermal Activation for removal of Gaseous Pollutants. J. Material Sci. 55: 334-339.

[6] Ecologix Environmental Systems (2008). Coconut-Shell and Wood Activated Carbon. Online.

Http://www.ecologixsystem.com. Accessed on 12 May, 2009.

[7] Hu, Z and Srinivasan, M. P. (2001): Mesoporous High Surface Area Activated Carbons. Microporous Mesoporous Mater., 34: 267-275.

[8] Sang, C. K., In, K. H. and Kyung, A. P. (1997): Preparation and Performance of Briquette type Activated Carbon based Bituminous Coal. J. Ind. Eng. Chem., 3(30): 218-222.

[9] Ambedkar, G. and Muniyan, M. (2011): Production and Characterization of Activated Carbon from Selected Local Materials. Adv. App. Sci. Res. 2 (4): 283.

[10] Sivakumar, P. and Palanisamy, N. (2010): Mechanistic Study of dye adsorption on to a novel non-conventional low-cost adsorbent. Adv. App. Sci. Res. 1(1): 58-65.

[11] Renugadevi, N., Anisha, G. and Lalitha, P. (2010): Characterization of Activated Carbon from Bituminous Coal through Chemical Activation. Adv. App. Sci. Res. 1(2): 102.

[12] Ajemba, R. O. (2012): Modification of the Physicochemical Properties of Udi Clay. Adv. App. Sci. Res. 3(4): 2042.

[13] Agalya, A., Palanisamy, N. and Sivakumar, P. (2012). Studies on Adsorptive Removal of Cationic dyes using a Novel nonconventional Activated Carbon. Adv. App. Sci. Res. 3(3): 1220-1230.

[14] Mane, P. C., Bhosle, A. B., Deshmukh, P. D. and Janagam, C. M. (2010). Production and Characterization of Activated Carbon from Bituminous Coal through Chemical Activation. Adv. App. Sci. Res. 1(3): 212.

[15] Rakholiya, V. V., Puranik, S. A. et al., (2012): COD Reduction using modifying Industrial Effluent Treatment. Adv. App. Sci. Res. 3(3): 1279.

[16] Shaarani, F. W. and Hameed, B. H. (2010). AmmoniaModified Activated Carbon for the Adsorption of 2,4dichlorophenol. The Chemical Engineering Journal, 169(1): 180-185.

[17] Yusuf, M. I., Ariahu, C. C. and Igbabul, B. D. (2012): Production and Characterisation of Activated Carbon from Selected Local Materials. Afr. J. Pure Appl. Chem. 6(9): 123131.

[18] Oyo, K. B. and Igbokwe, P. K. (2001): Production of Activated Carbon from Coconut-Shell. J. Chem. Soc. Niger., 33(1): 56-64. 
[19] Palnut, S. (2000): Production of Activated Carbon from Coconut Shells for Adsorption of Chromium (VI). Unpublished MSc Thesis in Chemical Engineering. Bangkok. King Mong University of Technology. Thombori. 5-80.

[20] ASTM (2002): Activated Carbon Standards. American Society for Testing and Materials. Online. Fritz Publication Http://www.fritz.com. Accessed on Nov. 2002.

[21] Aygum, A., Yenisoy, K. S. and Duman, I. (2003): Production of Granular Activated Carbon from Fruit Stones and Nutshells and Activation of their Physical, Chemical and Adsorption Properties. Microporous and Mesoporous Matter. 66: 189-195.
[22] Abubakar, M., Alechenu, A. A., Manase, A. and Mohammed, J. (2012): A Comparative Analysis and Characterization of Animal bones as Adsorbent. Advances in Applied Science Research, 3(5): 3089-3096.

[23] Calgon Carbon Corporation (2008): Activated Carbon, What is it, How does it work. Online Information Bulletin. www.calgoncarbon.com. Retrieved 2015-04-02.

[24] Savova, D., Apak, E., Ekinci, E., Yardim, F., Petrov, N., Budinova, T., Razvigorova, M. and Minkovo, V. (2001): Biomass Conversion to Carbon Adsorbents and Gas. Biomass Bioenerg., 21: 133-142. 